\title{
CRIAÇÃO DE VALOR NA INDÚSTRIA SUCROENERGÉTICA: AVALIAÇÃO DA FLEXIBILIDADE GERENCIAL EM ALTERAR O MIX DE PRODUÇÃ̃O
}

\author{
DEMETROFF, Caio Augusto ${ }^{1}$ \\ SANTOS, David Ferreira Lopes ${ }^{2}$ \\ ZANGRANDO, Pedro Wandscheer ${ }^{3}$
}

\begin{abstract}
RESUMO: Este estudo tem como objetivo captar a criação de valor da flexibilidade gerencial em alterar a produção de um grupo econômico que integra facilidades na produção de açúcar, etanol e energia utilizando como alicerce teórico a Teoria das Opções Reais. O objeto de estudo foi um grupo econômico localizado no interior do estado de São Paulo e a escolha deste grupo deve-se a seu posicionamento de destaque no setor juntamente à facilidade de acesso aos gestores. Para a construção do cenário foi projetado o fluxo de caixa do Grupo para sua produção de Açúcar, assim como levantados os investimentos necessários para a diversificação de sua produção, para que, só assim, fosse aplicada a Teoria das Opções Reais para se calcular a flexibilidade gerencial da escolha do mix produtivo anual da empresa. Por fim, estimou-se o valor da empresa com base nas possíveis variações de preços e suas probabilidades de ocorrência e comparou-se a avaliação baseada na Teoria das Opções Reais com o mesmo resultado obtido via Fluxo de Caixa Descontado, comprovando, assim, a eficácia da teoria para o caso em questão.
\end{abstract}

Palavras-Chave: Análise de Investimento; Fluxo de Caixa Descontado; Teoria das Opções Reais; Termelétrica; Usina de Açúcar e Etanol.

\section{CREATION OF VALUE IN THE SUCROENERGY INDUSTRY: EVALUATION OF MANAGEMENT FLEXIBILITY IN CHANGING THE PRODUCTION MIX}

SUMMARY: The objective of this study relied on measuring the value generation brought by the investments on diversifying the production facilities of a sugar plant, adding to the company the possibility of producing ethanol and generating electricity, based on the real options theory. The study was conducted in a sugar plant located at São Paulo state countryside and this company was select because it's highlighted position among the sugar production markets and the easy access to its managers. In order to build the basic scenario, it was estimated the cash flow for the sugar production and the investments needed in order to build the ethanol and electricity facilities, therefore, it was applied the real options theory to estimate the managing flexibility in the selection of the productive mix between sugar and ethanol for every year of operation. Therefore, it was estimated the company's valuation based on the behavior of prices and its probabilities and the result of the company's valuation based on the flexibility brought by real options theory was compared with the discounted cash flow method, assuring the efficiency of the real options theory.

Keywords: Investment Analysis; Discounted Cash Flow; Real Options Theory; Thermoelectric; Sugar and Ethanol Mills.

\section{INTRODUÇÃO}

O crescimento do setor sucroalcooleiro brasileiro neste século está relacionado à inovação tecnológica dos motores flex fuel, que permitiu o ressurgimento da demanda por etanol como fonte energética para o consumo automotivo (SPETIC; MARQUEZ; KOZAK, 2012; CAMARGO; OLIVEIRA, 2011). Concorreu, ainda, a favor do etanol, a sua natureza mais

\footnotetext{
${ }^{1}$ Graduado em Administração pela Unesp Jaboticabal e Especialista em Gestão Estratégica de Projetos pela FIA São Paulo. Atua como Coordenador de Planejamento Estratégico e Financeiro no Grupo CRM

${ }^{2}$ Professor adjunto na Faculdade de Ciências Agrárias e Veterinárias da Universidade Estadual Paulista (Unesp).

${ }^{3}$ Atua como Coordenador Socioassistencial da Prefeitura Municipal de Jaboticabal..
} 
renovável e com menor geração de gases de efeito estufa aos tradicionais derivados do petróleo e gás natural (GARCIA; LIMA; VIEIRA, 2015).

A diversificação do portfólio das tradicionais usinas sucroalcooleiras foi ampliada com a possibilidade de associação nestas plantas industriais de centrais de usinas termelétricas que conseguem direcionar a geração de calor do processo produtivo para produção de energia elétrica (MOTA; MACHADO; MORAES, 2015; MANDEGARI; FARZAD; GÖRGENS, 2017). A possibilidade de geração de bioenergia trouxe uma nova dinâmica a este tradicional setor, que respondeu por 5,2\% da oferta de energia elétrica do Brasil em 2015 e passou a ser considerado estratégico na matriz energética brasileira e, por isso, denominado recentemente como setor sucroenergético (BRASIL. MINISTÉRIO DE MINAS E ENERGIA, 2016).

A importância destas inovações para este setor tem motivado múltiplas investigações quanto à viabilidade econômica destas alternativas para as usinas já estabelecidas e para proposições de novas plantas industriais (REZENDE; RICHARDSON, 2015).

No entanto, a diversificação do portfólio das usinas que passaram a ter o potencial de três produtos principais (açúcar, etanol e energia), a partir de uma única matéria-prima (cana-deaçúcar) trouxe uma questão pouco explorada economicamente que é o valor da flexibilidade gerencial em alterar o mix de produção das unidades produtivas (BASTIAN-PINTO; BRANDÃO, 2007; MANDEGARI; FARZAD; GÖRGENS, 2017). Bastian-Pinto e Brandão (2007) discutiram as diferenças entre metodologias de precificação das opções substituindo açúcar por etanol, porém, não há inclusão de energia e, tampouco, a análise do portfólio de mix de produção.

Assim, as usinas sucroenergéticas podem ter três produtos cujos mercados são distintos e seguem padrões de volatilidade diferentes, no entanto, a inércia da gestão de operações, associada as decisões de tesouraria junto aos compromissos dos contratos futuros de opções e de venda de energia "firme" não permitem que as alterações no mix sejam realizadas a qualquer tempo e, tampouco, de forma informal.

Assim, a valoração de plantas industriais sucroenergéticas com os três produtos principais deve considerar o valor da flexibilidade gerencial em alterar o mix de produção. Não obstante, compreender a importância do valor desta decisão e discutir modelos financeiros que sejam capazes de orientar gestores no processo decisório, tornam-se importantes para este setor que é o maior produtor mundial de açúcar e etanol de cana de açúcar do mundo (CONAB, 2013). Atuando de forma importante na economia nacional uma vez que a safra de 2014/2015 mostra que as 423 usinas e destilarias geram 4,5 milhões de empregos diretos e indiretos e representam 1,3\% do PIB brasileiro (MANOEL; SANTOS; MORAES, 2016; JORNALCANA, 2015). 
Ressalta-se, contudo, que este potencial de aplicação não se restringe ao Brasil, mas aos países com produção significativa de cana-de-açúcar como Índia, China e Tailândia que são os maiores produtores após o Brasil e já discutem a importância econômica dessa diversificação, bem como, pode ser estendido para outras fontes de bioenergia como milho, soja, óleo de girassol, entre outros (HETTINGA et al., 2009; FAO, 2013).

Portanto, esse estudo se posiciona na área das finanças corporativas onde se identifica um gap teórico-prático quanto a análise da criação de valor da flexibilidade gerencial em alterar a produção de um grupo de usinas que integram facilidades na produção de açúcar, etanol e energia.

Procura-se construir um modelo de avaliação que inclua as alternativas de investimentos nos projetos estratégicos desta indústria e a valoração do acréscimo de riqueza proveniente do aumento de flexibilidade de negócios que pode ser assumida pelos administradores.

Desta forma, a motivação para realização deste estudo residiu na seguinte questão: qual o valor da flexibilidade gerencial em alterar o mix de produção de um grupo de usinas sucroenergéticas com o portfólio de açúcar, etanol e energia?

A avaliação de investimentos por opções reais é empregada na presença de flexibilidade gerencial em alterar o curso do projeto mediante a identificação, a priori de incertezas (COPELAND; ANTIKAROV, 2001; BASTIAN-PINTO; BRANDÃO, 2007). Essa técnica ganhou espaço nas avaliações de criação de valor das empresas, em função das limitações do método baseado no Fluxo de Caixa Descontado (FCD) (PINDYCK, 1993; TRIGEORGIS, 1996).

Desta forma, esse estudo aplica a abordagem metodológica de avaliação de investimento consolidada nas finanças corporativas, mas com uso marginal na indústria sucroenergética, assim como, valora a capacidade de criação de valor dos principais investimentos nesta indústria, a partir da diversificação da produção entre açúcar e etanol mais a produção de energia decorrente.

Para melhor organizar a estrutura da pesquisa realizada, este artigo foi dividido em mais quatro seções além desta introdução. A segunda seção aborda os fundamentos teóricos da modelagem por opções reais e traz evidências de aplicações no setor sucroenergético. Na terceira seção tem-se os material e métodos que permitiram a realização da pesquisa empírica, por meio de um estudo de caso em grupo econômico do setor sucroenergético. A quarta seção apresenta os resultados e as discussões inerentes às evidências deste estudo e a literatura. Por fim, as considerações finais apresentam as implicações e limitações deste estudo, além de sugestões para pesquisas futuras. 


\section{REFERENCIAL TEÓRICO}

Para este estudo, a revisão da literatura permeia os fundamentos da teoria de investimento, métodos para elaboração e avaliação de projetos e as técnicas utilizadas para o processo decisório. Procurou-se, também, nesta fundamentação teórica a discussão dos pressupostos junto a resultados empíricos no agronegócio, em especial, nos setores sucro e energético.

\subsection{Teoria do Investimento}

Keynes (1996) categoriza o resultado econômico dos ativos de uma organização a partir da eficiência marginal dos investimentos de capital que são expressos nas diferenças entre a rentabilidade e o custo de capital. Nesta direção, os investimentos são realizados até o momento em que o retorno iguala o custo de capital (CASAGRANDE; CEREZETTI, 2014). Todavia, ressalta-se as restrições apontadas pela psicologia cognitiva quanto ao princípio da racionalidade econômica (TVERSKY; KAHNEMAN, 1986).

A eficiência marginal do capital, para Keynes (1996) é instável do ponto de vista prático, dado que é estimada com base nas projeções e expectativas dos agentes econômicos, que apresentam, por sua vez, limitações racionais, além de acesso restrito às informações e o fato de que estão inseridos em um cenário repleto de incertezas, principalmente acerca das condições de longo prazo (CASAGRANDE; CEREZETTI, 2014).

A teoria keynesiana considera, ainda, que a propensão dos agentes ao investimento está diretamente atrelada também à taxa de lucro estimada e ao nível de retorno de juros decorrentes do montante de renda das organizações. Sendo assim, o investimento só é viável quando a taxa de retorno é superior ao custo de capital (KEYNES, 1996).

\subsection{Métodos de Análise de Investimento}

Damodaran (2002) afirma que existem três principais abordagens de avaliação de investimentos utilizadas por acadêmicos e profissionais: fluxo de caixa descontado, a avaliação relativa (ou por múltiplos) e a avaliação de direitos contingentes (Opções).

A análise de investimentos é de ampla importância para as organizações e se constitui uma das principais funções da gestão financeira (GRAHAM; HARVEY, 2001). Assim, como no trabalho de Graham e Harvey (2001) para empresas norte americanas, Frezatti et al. (2012) evidenciaram que as principais empresas brasileiras utilizam as técnicas derivadas do Fluxo de Caixa Descontado (FCD) nas suas análises de investimentos, em especial: Valor Presente Líquido (VPL) e Taxa Interna de Retorno (TIR).

Por ser um método de avaliação baseado em fluxos de caixa futuros e suas estimadas taxas de desconto, o FCD é o modelo de avaliação mais facilmente aplicado às empresas que 
possuam, na atualidade, fluxos de caixa positivos e em que exista um substituto confiável para o risco que possa alicerçar os cálculos das taxas de desconto (DAMODARAN, 2002).

Já uma avaliação mais prática e amplamente utilizada nos mercados financeiros, tem-se a avaliação por múltiplos que se baseia em indicadores comparáveis para confrontar os resultados de cada empresa com seus pares setoriais. Costumeiramente o analista financeiro pode enfrentar dificuldades para selecionar empresas similares, o que torna mais complicado o emprego desta ferramenta na avaliação de projetos em ativos reais (DAMODARAN, 2002).

O último método de análise de investimentos é a avaliação por direitos contingentes ou opções. O alicerce básico para a avaliação por opções vem da limitação do FCD em incorporar as incertezas inerentes as premissas do fluxo de caixa; quase sempre o elevado nível volatilidade impacta em uma taxa de desconto mais elevada, com efeito, há redução no valor presente do ativo, muito embora alternativas mitigadoras ou compensatórias possam ser exercidas no futuro (COSTA; SAMANEZ, 2014).

As opções podem ser de dois tipos: financeira e real. Opções em que o ativo subjacente é um ativo financeiro como títulos de renda fixa resgatável, ações, contratos futuros de câmbios e commodities, entre outros são classificadas como opções financeiras. Opções sobre investimentos em ativos reais como plantas industriais, máquinas e equipamentos, imóveis entre outros são as opções reais (DAMODARAN, 2002).

O entendimento que os investimentos empresariais devem ser classificados como uma opção, isto é, um direito que pode ser exercido (totalmente ou parcialmente), modificado ou mesmo abandonado é a principal mudança frente a metodologia tradicional do fluxo de caixa descontado (TRIGEORGIS, 1996; BRANDÃO; DYER; HAHN, 2012).

Damodaran (2002) ainda levanta que, apesar de seu caráter inovador e revolucionário, o modelo de avaliação por opções esbarra em algumas dificuldades e limitações nos casos em que avalia como opções de longo prazo ativos não negociados, o que gera a necessidade de que os dados de entrada de valores financeiros sejam estimados.

\subsubsection{Fluxo de Caixa Descontado (FCD)}

O FCD é o principal método para valorar empresa e avaliar ativos individuais (GRAHAM; HARVEY, 2001; DAMODARAN, 2002; FREZATTI et al., 2012). Para utilização desse método é necessário o desconto do fluxo de caixa livre perante o custo de capital, o que demonstra a premissa keynesiana por trás da técnica, em especial, porquê se espera que o somatório do FCD seja maior que o investimento realizado, conforme demonstrado na Equação 1 (CUNHA, MARTINS; ASSAF NETO, 2014).

$$
\text { Valor da Empresa }=\sum_{t=1}^{t=n} \frac{F C \text { da Empresa }}{(1+W A C C)^{n}}
$$


Onde:

FC da Empresa $=$ Fluxo de Caixa estimado no período $n$;

WACC $=$ Weighted Average Cost of Capital (Custo Médio Ponderado de Capital).

A partir do FCD, pode-se extrair o período de recuperação do investimento Payback (Simples ou Descontado), a TIR, o VPL além de outros indicadores derivados (JOHANN et al., 2014).

Payback simples - Metodologia fácil, simples e direta que visa comparar o tempo estimado que é preciso para a recuperação do capital financeiro dispendido em um projeto com o período de tolerância de uma organização para a retomada de seu capital (JOHANN et al., 2014). A Equação 2 apresenta o método de cálculo do payback.

$$
\text { Payback }=\frac{\text { Investimento Total }}{\overline{F C \text { empresa }}}
$$

Payback descontado - No momento em que se inclui o valor do dinheiro no tempo no cálculo do payback simples, obtém-se o período estimado de recuperação do investimento remunerado (JOHANN et al., 2014). Esta metodologia inclui o custo de oportunidade do capital investido (Equação 3), porém como sua proposta é determinar o tempo de recuperação do investimento, desconsidera-se o potencial de criação de valor do projeto em todo o seu curso (CUNHA; MEDEIROS; WANDER, 2014).

$$
\text { Payback Descontado }=\frac{\sum_{i=0}^{n} \frac{\text { Investimento }_{i}}{(1+i)^{n}}}{\overline{F C D}}
$$

As equações 2 e 3 podem trazer vieses para a análise quando há diferenças relevantes entre eles (em especial no descontado), assim, a forma mais efetiva é realizar o somatório dos fluxos de caixa (empresa e/ou descontado) em ordem cronológica até o período em que o total seja equivalente ao investimento (DAMODARAN, 2002; JOHANN et al., 2014).

Valor Presente Líquido (VPL) é o método de avaliação que demonstra o potencial de criação de riqueza de um projeto de investimento para a organização (DAMODARAN, 2002). É obtido através da soma de todos os fluxos de caixa descontados com seus valores convertidos no momento inicial do investimento (Equação 4). Caso o valor do VPL seja maior do que zero, o investimento atende as premissas econômicas para ser aceito (COPELAND; ANTIKAROV, 2001).

$$
V P L=\sum_{t=1}^{t=n} \frac{F C L \text { do } \text { Projeto }_{n}}{(1+W A C C)^{n}}-I_{0}
$$


Taxa Interna de Retorno (TIR) representa a taxa de juros necessária para que o valor do VPL de um investimento seja zero (Equação 5) (DAMODARAN, 2002). Por outro modo, a TIR representa a taxa de rentabilidade do projeto, sendo sempre comparada com o WACC ou a Taxa Mínima de Atratividade (TMA) (FREZATTI et al., 2012; JOHANN et al., 2014; MACEDO; NARDELLI, 2011). Desta forma, o projeto será aceito se a TIR for superior ao WACC e, sendo assim, representa em essência o princípio keynesiano do processo de decisão para investimentos. Não por outro motivo entre as técnicas baseadas do FCD a TIR é àquela mais utilizada pelo mercado (GRAHAM; HARVEY, 2001).

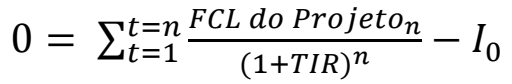

A principal crítica teórica ao FCD é que esta metodologia não considera a flexibilidade gerencial, pois tem como pressuposto que o investimento é uma obrigação a ser realizada tal qual foi planejada (TRIGEORGIS, 1996; COPELAND; ANTIKAROV, 2001). A partir dessa limitação, as finanças corporativas passaram a empregar os conceitos baseados nas opções financeiras, em especial, da formulação de Black-Sholes (TRIGEORGIS, 1996; BRANDÃO. DYER, 2005; COPELAND; KOLLER; MURRIN, 2002).

\subsubsection{Teoria das Opções Reais}

A teoria das opções reais é uma forma de análise de investimento que foi amplamente discutida a partir de Tourinho (1979), Pindyck (1993) e Trigeorgis (1996). As opções podem ser diversas em forma e aplicação, em especial, no agronegócio (PANTOJA, SAMANEZ, et al., 2016; MACEDO; NARDELLI, 2011).

Brandão e Dyer (2005) afirmam que uma avaliação de projeto com base na metodologia das opções reais agrega perspectivas interessantes no que tange à ação gerencial. Para eles, esta metodologia permite ao administrador financeiro quantificar o valor de uma gestão mais ativa, retornando como resultado um modelo de um valor presente expandido, que agrega ao modelo clássico de VPL as possibilidades de adaptações estratégicas ao decorrer dos projetos.

Copeland e Antikarov (2001) classificam as opções sobre os projetos de investimento em cinco tipos (excludentes entre si), porém, como por ele reconhecido, não exaustivos. São eles:

a) Opção de Abandono - Ocorre no momento em que se observa um resultado ruim após algum tempo decorrido da realização do projeto e é equivalente a opção do modelo americano de venda (MACEDO; NARDELLI, 2011).

b) Opção de Adiar - Equivalente a opção de compra americana é observada quando o pode-se optar, com base em suas premissas de cálculo, por postergar a realização do projeto.

c) Opção de expansão - Trata-se da opção de expandir em escala a operação de dado projeto. Equivalente, também, à opção americana de compra. 
d) Opção de Contração - É a opção de reduzir a produção ou a dimensão de um projeto, como acontece, por exemplo, em casos de investimentos em operações modulares. Equivalente a opção americana de venda.

e) Opção de Alternância - Caracteriza a flexibilidade que o administrador possui de alternar entre as decisões possíveis ao decorrer do projeto, de acordo com as condições analisadas no andamento do empreendimento. Equivale tanto à opção americana de compra.

Existem três formas mais utilizadas para se valorar as opções, dentre elas temo: o modelo Black-Sholes, a Simulação Monte Carlo e o modelo binomial de Cox, Ross e Rubinstein (1979) (SANTOS; ZOTES, 2010).

O método Monte Carlo é uma forma de solução das opções reais quando há diversas variáveis estocásticas na composição do fluxo de caixa. O método tem largo uso em função da utilização de softwares que descartam a necessidade de escrever equações diferenciais e facilita a simulação direta dos processos estocásticos de diversas fontes de incerteza simultaneamente (PANTOJA, 2013).

Os modelos que são estimados por Monte Carlo por Cadeia de Markov (MCMC) consistem em uma simulação feita para combinar as várias fontes de incerteza em uma única incerteza representativa, definindo assim um comportamento estocástico (BRANDÃO; DYER; HAHN, 2005).

Já Cox, Ross e Rubienstein (1979) desenvolveram um modelo em que o processo estocástico contínuo do preço do ativo descrito pela equação é substituído por dois estados up e down, que correspondem a uma alta e uma baixa do preço, considerando a volatilidade e probabilidade de ocorrência (JOAQUIM et al., 2015).

Ainda sobre os métodos de TOR deve-se ressaltar que são divididos em duas abordagens: tempo contínuo e tempo descontínuo (CUNHA; MEDEIROS; WANDER, 2014; MILLER; PARK, 2002).

Para Damodaran (2002), Black e Scholes publicaram em seu pioneiro estudo um modelo de avaliação das opções que foi o primeiro a solucionar uma Equação Diferencial Parcial (EDP) e sua definição de opção só se dará através das condições de contorno da EDP e até a atualidade a formulação de opções de Black-Sholes é uma referência para as opções financeiras cujo direito de exercício só pode ocorrer no vencimento da opção (opção europeia) (PANTOJA, 2013).

Para este trabalho, será o utilizado o método binomial, pois pressupõe a possibilidade da opção antes do prazo de exercício (opção americana) e, em função, da sua visualização mais prática e assertiva ao empresário, frente aos demais métodos (SANTOS; ZOTES, 2010; CUERVO; BOTERO, 2014). Assim, o seu processo de cálculo será apresentado na sequência. 


\subsubsection{Modelo Binomial}

$\mathrm{Na}$ abordagem de opções reais existem três métodos diferentes de valoração das opções embutidas nas alternâncias de investimentos, entre eles estão o Movimento Geométrico Browniano (MGB), o Movimento de Reversão à M dia (MRM) e o MRM com saltos de Poisson (RODRIGUES et al., 2013).

Processos mais realistas e com saltos discretos utilizam a equação diferencial a seguir (Equação 6) que ilustra um processo simples de Poisson (PANTOJA, 2013).

$$
d x=f(x, t) d t+g(x, t) d q
$$

O MGB é um caso particular do Processo de Itô, muito utilizado para modelar preço de ações, produtos e variáveis econômicas e financeiras, nele temos a tendência é um crescimento ou queda exponencial e os preços têm uma distribuição lognormal com variância crescendo no horizonte temporal (PANTOJA, 2013).

A maior parte dos estudos de opções reais assume que fatores de incerteza seguem um MGB (PANTOJA, 2013).

$$
x_{t}=x_{t-1} * \exp \left\{\left(\alpha-\frac{1}{2} \sigma^{2}\right) \Delta t+\sigma \varepsilon \sqrt{\Delta t}\right\}, \varepsilon \sim N(0,1)
$$

As fórmulas para os parâmetros ' $u$ ' para subida e ' $d$ ' para descida do modelo binomial estão expressas nas Equações 8 e 9 (BRANDÃO; DYER, 2005) .

$$
\begin{aligned}
& u=e^{\sigma \sqrt{\Delta t}} \\
& d=e^{-\sigma \sqrt{\Delta t}}
\end{aligned}
$$

Nas Equações 8 e 9, ' $e$ ' é o logaritmo de Neper, ' $\sigma$ ' é a volatilidade anual do ativo subjacente e ' $\Delta \mathrm{t}$ ' é o intervalo de tempo entre o momento atual e o vencimento da opção.

Para simplificação matemática do processo de cálculo do valor das opções projetadas para o futuro pelo MGB para o presente, utiliza-se a abordagem probabilística neutra ao risco, conforme as Equações 10 e 11 (COPELAND; ANTIKAROV, 2001).

$$
\begin{aligned}
& p=\frac{(1+R f)-d}{(u-d)} \\
& q=1-p
\end{aligned}
$$

As probabilidades $p$ e $q$ são utilizadas para os movimentos de subida e descida respectivamente. 
A teoria da probabilidade neutra ao risco demonstra que as probabilidades objetivas não interferem no cálculo do preço de cada uma das opções, sendo assim, não se faz necessário ajustar a taxa de desconto para valorar as opções (PAMPLONA et al., 2013). Copeland e Antikarov (2001) concluem que, mesmo que os resultados diferirem entre si nos primeiros períodos da árvore, com o passar do tempo de análise os modelos tendem a convergir, considerando como parâmetro o modelo de Black-Scholes.

O MRM é um processo alternativo ao MGB e que sua modelagem é mais complexa mas leva a menos erros de superestimação do valor das opções reais, e o MRM parte da lógica que fundamenta a microeconomia que quando os preços estão abaixo de sua média, sua demanda tenda a aumentar e a produção tende a diminuir por conta da elevação dos preços, e vice-versa (PANTOJA, 2013).

A utilização do MRM para modelagem em commodities é algo corriqueiro e seus movimentos de alta e baixa dos preços por conta da falta de oferta ocasional são os principais argumentos para a ampla utilização do MRM. Para ser utilizado na simulação dos preços é necessário estimar os parâmetros de volatilidade, a média de longo prazo e a velocidade de reversão da média, que se aplica por meio de uma regressão linear nos preços históricos das commodities (PANTOJA et al., 2016).

Assim como o MGB, a análise pelo MRM por meio do Monte Carlo é necessária uma equação discreta que descreve, respectivamente a simulação real e a neutra ao risco do modelo (PANTOJA, 2013):

$$
P_{t}=\exp \left\{\ln \left[P_{t-1}\right] e^{-\eta \Delta t}+\left[\ln (\bar{P})-\frac{\sigma^{2}}{2 \eta}-\frac{\mu-r}{\eta}\right]\left(1-e^{-\eta \Delta t}\right)+\sigma \sqrt{\frac{1-e^{-2 \eta \Delta t}}{2 \eta}} \mathrm{N}(0,1)\right\}
$$

Temos a fórmula onde $\mu$ é a taxa ajustada ao risco, $r$ é a taxa livre de risco, $\eta$ é a velocidade de reversão à média e $\frac{\mu-r}{\eta}$ é o prêmio de risco normalizado (PANTOJA, 2013).

\subsection{Características da Valoração em Ativos Energéticos}

A valoração de ativos energéticos tem sido alvo de diferentes estudos, sendo que o uso para investimentos associados a biomassa e de forma específica na indústria sucroenergética é ainda um desafio. O Quadro 1 apresenta estudos empíricos que utilizaram a Teoria de Opções Reais na valoração de ativos energéticos. Para o levantamento dos artigos utilizou-se a base Scopus, Web of Science e Google Acadêmico, sendo que só foram utilizados artigos com referee e publicados em revistas ou eventos especializados. Os termos de busca fora: Option Real Theory e Energy no Resumo/Abstract. 
Quadro 1 - Estudos empíricos que utilizaram a Teoria de Opções Reais na valoração de ativos energéticos

\begin{tabular}{|c|c|c|}
\hline Autor(es) e Ano & Escopo do estudo & Resultados \\
\hline $\begin{array}{l}\text { (BASTIAN-PINTO } \\
\text { BRANDÃO, 2007) }\end{array}$ & $\begin{array}{l}\text { Opção de conversão de } \\
\text { produção de açúcar para } \\
\text { etanol }\end{array}$ & $\begin{array}{l}\text { A inclusão da opção de conversão aumenta o valor do } \\
\text { investimento, em especial, quando modelada pelo } \\
\text { MGB. }\end{array}$ \\
\hline $\begin{array}{ll}\text { (BOOMSMA } & \text { e } \\
\text { LINNERUD, 2016) } & \end{array}$ & $\begin{array}{l}\text { As opções no mercado de } \\
\text { energia renovável e seus } \\
\text { benefícios }\end{array}$ & $\begin{array}{l}\text { Ao utilizar o MGB para modelar as opções de incerteza } \\
\text { do mercado e incerteza política mostrou que as } \\
\text { empresas que optaram pelas opções entre venda a preço } \\
\text { de mercado ou a preço tarifado tiveram menos risco. }\end{array}$ \\
\hline $\begin{array}{l}\text { (BOOMSMA, } \\
\text { MEADE e FLETEN, } \\
\text { 2012) }\end{array}$ & $\begin{array}{l}\text { As opções no mercado de } \\
\text { energia renovável } \\
\text { analisando o momento e } \\
\text { capacidade de escolha do } \\
\text { investimento }\end{array}$ & $\begin{array}{l}\text { Por meio do modelo de Monte Carlo nas opões } \\
\text { conseguiu-se ver que a opção de venda por tarifa fixa } \\
\text { leva a investimentos mais cedo e já o preço de } \\
\text { certificado renováveis representa uma opção para } \\
\text { grandes projetos. }\end{array}$ \\
\hline $\begin{array}{l}\text { (DIAS, } \quad \text { BASTIAN- } \\
\text { PINTO, et al., 2011) }\end{array}$ & $\begin{array}{l}\text { A opção de uma planta de } \\
\text { cogeração numa usina de } \\
\text { cana-de-açúcar. }\end{array}$ & $\begin{array}{l}\text { Através do modelo de reversão a média conseguimos } \\
\text { mostrar que o investimento em planta de coogeração } \\
\text { agrega valor a empresa e deve ser algo incentivado pois } \\
\text { apenas } 50 \% \text { das usinas atuais atuam no mercado de } \\
\text { cogeração de energia. }\end{array}$ \\
\hline $\begin{array}{l}\text { INIESTA, SOLIÑO e } \\
\text { GALERA, 2015) }\end{array}$ & $\begin{array}{l}\text { As opções inseridas no } \\
\text { contrato em uma planta de } \\
\text { energia eólica }\end{array}$ & $\begin{array}{l}\text { Aplicando o modelo de Monte Carlo nas opções } \\
\text { mostrou que a existência das opções na lei que } \\
\text { regulamenta a energia renovável da Espanha traz uma } \\
\text { confiabilidade para o investidor que consegue simular } \\
\text { suas receitas }\end{array}$ \\
\hline $\begin{array}{l}\text { (KIENZLE e } \\
\text { ANDERSSON, 2009) }\end{array}$ & $\begin{array}{l}\text { As opções em um Hub de } \\
\text { eletricidade na geração de } \\
\text { energia }\end{array}$ & $\begin{array}{l}\text { Por meio do modelo de Monte Carlo mostraram que o } \\
\text { Hub de Energia é algo que combinado as opções mostra } \\
\text { um valioso caminho para futuros investimentos em } \\
\text { plantas de geração de multi-energia. }\end{array}$ \\
\hline (PANTOJA, 2013) & $\begin{array}{l}\text { A avaliação de uma planta } \\
\text { de energia eólica com } \\
\text { troca na opção de venda de } \\
\text { energia }\end{array}$ & $\begin{array}{l}\text { A utilização de opções entre venda no curto e longo } \\
\text { prazo, sendo o curto prazo modelado por MRM e o } \\
\text { longo prazo por MGB levou a ganho significativo no } \\
\text { valor da planta. }\end{array}$ \\
\hline $\begin{array}{l}\text { (PANTOJA, } \\
\text { SAMANEZ, et al., } \\
\text { 2016) }\end{array}$ & $\begin{array}{l}\text { A opção de troca entre } \\
\text { produção de açúcar e } \\
\text { etanol }\end{array}$ & $\begin{array}{l}\text { As opções foram modeladas por MRM e mostraram } \\
\text { que as usinas optantes pela flexibilização apresentaram } \\
\text { maiores benefícios financeiros e fiscais. }\end{array}$ \\
\hline $\begin{array}{l}\text { (SAMANEZ } \\
\text { COSTA, 2014) }\end{array}$ & $\begin{array}{l}\text { A opção de swing no } \\
\text { mercado de Gás Natural }\end{array}$ & $\begin{array}{l}\text { Através do modelo de Schawtz e Smith (2000) } \\
\text { analisaram como a opção de swing beneficia as } \\
\text { empresas de Gás Natural. }\end{array}$ \\
\hline $\begin{array}{l}\text { (SIMÕES, } \\
\text { OLIVEIRA, et al., } \\
\text { 2011) }\end{array}$ & $\begin{array}{lcc}\text { Opções de swing } & \text { no } \\
\text { mercado brasileiro } & \text { de } \\
\text { energia elétrica }\end{array}$ & $\begin{array}{l}\text { Aplicando o modelo MRM para os preços conseguimos } \\
\text { observar que o valor marginal de opões de swing } \\
\text { acrescentadas a um contrato de fornecimento de energia } \\
\text { tem valor decrescente com o aumento destas opções. }\end{array}$ \\
\hline
\end{tabular}

Fonte: elaborado pelos autores

Nota-se que há poucos estudos para o setor sucroenergético e aqueles que trabalharam o setor não abordaram a opção de diversificação dos três principais produtos (açúcar, etanol e energia) para uma mesma planta industrial. Não obstante, todos os estudos demonstraram o potencial da TOR para mensurar as flexibilidades gerenciais neste segmento, o que corrobora a importância e a originalidade desta abordagem para avaliação de investimento neste setor.

\section{METODOLOGIA}

Para a realização desse trabalho foi executada uma pesquisa de natureza exploratória, usando-se uma abordagem quantitativa a partir de dados primários oriundos de um estudo de caso em um grupo econômico que atua no setor sucroenergético, estabelecido na Região 
administrativa de Ribeirão Preto - SP, sendo esta a maior região produtiva do setor no Brasil com mais de 26 usinas (JORNALCANA, 2015).

O uso do estudo de caso como abordagem metodológica deve-se a natureza do fenômeno que ocorre de fato no âmbito das organizações, cujo acesso às informações e o contexto do investimento se dá mediante a proximidade da relação entre pesquisador e objeto, cujo foco é buscar esclarecer uma decisão, ou um conjunto de decisões, iniciando pelo motivo da tomada desta decisão até a forma de implementação e seus resultados (YIN, 2015).

Mesmo apresentando-se como melhor metodologia de pesquisa para este trabalho, o estudo de caso, como apontado por Steiner (2011) esbarra em algumas limitações, tais quais: dificuldade de escolha de casos realmente relevantes, baixa representatividade e possibilidade de generalização, pouca capacidade de avaliar o peso casual de cada uma das variáveis que impactam o objeto de estudo. As limitações devem ser consideradas para fins comparativos.

Os dados para realização da pesquisa foram obtidos junto às fontes externas e internas à empresa objeto do estudo. Esse procedimento é importante para triangulação das informações e verificação da sua confiabilidade (GODOY, 2006).

Inicialmente, houve o levantamento de pesquisas realizadas (apontadas no Quadro 1) que contribuíram com a formalização do processo quantitativo de mensuração. Em adição, foram utilizadas as bases de dados do Quadro 2 como fontes de informação para um melhor entendimento da estrutura e condicionantes dos investimentos.

Quadro 2 - Relação de fontes de dados e propósitos de aplicação dos mesmos

\begin{tabular}{|l|l|}
\hline FONTE & PROPÓSITO \\
\hline Controles Internos do Grupo & $\begin{array}{l}\text { Elementos condicionantes, Investimentos e Custos da produção de açúcar } \\
\text { e etanol. }\end{array}$ \\
\hline $\begin{array}{l}\text { ÚNICA - União da Indústria de Cana de } \\
\text { Açúcar }\end{array}$ & $\begin{array}{l}\text { Informações sobre os processos de produção de açúcar, etanol e energia } \\
\text { elétrica, por meio da seção “estudos” disponíveis no domínio eletrônico; } \\
\text { além de outras informações do setor. }\end{array}$ \\
\hline Copersucar & Preços históricos dos produtos comercializados de forma cooperada. \\
\hline $\begin{array}{l}\text { ANEEL - Agência Nacional de Energia } \\
\text { Elétrica }\end{array}$ & Preço dos leilões de energia elétrica proveniente de biomassa \\
\hline CEPEA - ESALQ/USP & Indicadores de preço e informações da indústria \\
\hline
\end{tabular}

Fonte: elaborado pelos autores

Em adição, foram tomadas informações das seguintes fontes dentro da organização:

a) Análise de documentos internos: demonstrativos financeiros padronizados; esquema do projeto industrial; procedimentos de operação e processo, entre outros.

b) Entrevistas semiestruturadas: depoimento do gerente de produção do grupo, supervisores de suprimento, operação e distribuição; gerente comercial; recursos humanos e controladoria. As informações foram anotadas em caderno de campo. 
c) Observação e registros: Acompanhou-se, in loco, todo o processo operacional para produção do açúcar, etanol e energia elétrica. Para evitar vieses um dos autores não acompanhou o processo e discutiu com os demais os resultados verificados.

Assinala-se que, o levantamento de dados apresentou como limitações a falta de estruturação de alguns dados internos, assim como ausência de algumas ferramentas gerenciais que seriam importantes para o estudo (como a apuração precisa do custo de produção por tipo de produto por exemplo). Desta forma, alguns destes itens foram desenvolvidos pelos pesquisadores no curso da pesquisa, sendo validados pelos gestores no final.

O período da pesquisa empírica transcorreu durante os meses de julho/2015 a março/2016.

A pesquisa ocorreu em quatro etapas distintas visando assim atingir o objetivo geral do trabalho, sendo estas: 1. Encontrar o valor presente para o grupo na hipótese da produção somente de açúcar; 2. Estimar o incremento de valor trazido ao grupo pelo investimento na diversificação da produção para o etanol; 3. Estimar o incremento de valor do grupo com o investimento na produção de açúcar, etanol e cogeração de energia; 4. Valorar a flexibilidade de escolha pelo mix produtivo de cada safra.

\section{ANÁLISE DOS RESULTADOS}

Segundo o gestor de produção industrial, o grupo conta com três plantas fabris, dentre elas duas possuem condições de produzir todos os produtos operados pelo grupo (Açúcar Branco e Bruto; Etanol Anidro e Hidratado) enquanto uma das unidades fora construída apenas com destilaria, ou seja, não apresenta condições para produzir açúcar, apenas, etanol.

Para o presente estudo, que visa escalonar o valor agregado ao grupo comparando os investimentos e seus retornos para a diversificação de sua produção, ou seja, a transição de uma planta de produção de açúcar para um site capaz de gerar um mix produtivo de Açúcar e Etanol e, posteriormente, o incremento dos ativos para a cogeração de energia via queima do bagaço de cana; o cenário inicial para análise se pauta na operação para a safra 2015/2016, considerando, somente, a produção de açúcar em uma de suas duas unidades que possuem esta possibilidade, sendo descartados todos os investimentos e custos inerentes a produção de etanol.

O segundo ponto de análise parte da premissa de que os ativos produtivos da destilaria seriam análogos ao prêmio de mercado pela opção de possuir um mix produtivo entre açúcar e etanol; e, no terceiro momento, estudou-se o valor dos ativos produtivos das termoelétricas de propriedade do grupo como prêmio de mercado pela opção de se produzir o mix entre açúcar e etanol, adicionado da cogeração de energia elétrica.

Sendo assim, o primeiro passo foi a construção do cenário de produção simulando a operação do grupo com o mix 100\% de açúcar para determinar o valor da empresa. 
Para a estimativa da taxa de desconto, aplicou-se o modelo do WACC. O cálculo embasou-se em alguns dados presentes no balanço societário como: total de capital de terceiros em posse do grupo ( $\mathrm{R}$ \$ 682,02 milhões), valor do patrimônio líquido ( $\mathrm{R}$ \$ 508,82 milhões) e também o custo estimado nominal da dívida da empresa em 12,36\% a.a.. A taxa livre de risco do país foi estimada em $12,11 \%$ a.a., quando do período da pesquisa.

Como o grupo não possui capital aberto, para o cálculo do beta (risco sistemático do grupo), levou-se em conta a média dos betas de outras duas empresas comparáveis do setor (São Martinho e Biosev, considerando dados dos últimos 36 meses (2014/2016) (resultando em um índice de 0,71$)$. Utilizou-se o prêmio de mercado de 6,9\%. Sendo assim, tem-se:

$$
\begin{aligned}
& k_{e}=0,1211+0,71(0,069) ; k_{e}=0,17 \\
& W A C C=0,17 \times\left[\frac{508.822}{682.024+508.822}\right]+0,12 \times(1-0,34) \times\left[\frac{682.024}{682.024+508.822}\right]=11,94 \%
\end{aligned}
$$

Além da estimativa da taxa de desconto, para a construção dos fluxos de caixa foi levantado com a gestão do grupo o valor estimado dos investimentos anuais na atualização das plantas industriais e atividades agrícolas para o ano safra em questão. O valor informado foi de $\mathrm{R} \$ 11,99$ milhões/ano.

Para a construção da Receita tomou-se a capacidade real da empresa, comparada com o seu histórico de produção, adicionado ao preço açúcar já travado pela empresa para a safra 2015/2016. Não será informada a capacidade da empresa, para não permitir a sua identificação. Os custos foram determinados, a partir da segregação das atividades agrícolas e industriais, sendo que este exercício foi realizado pelos autores, pois a empresa não tinha tais informações com confiabilidade.

A Tabela 1 apresenta o FC de uma das unidades considerando somente a produção de açúcar. A evolução dos valores no curso do tempo deve-se a média da variação nominal identificada nos históricos da empresa. A taxa de desconto, também, é nominal.

A Tabela 2 apresenta o FC com a inclusão do etanol que será discutida na sequência do texto. 
Tabela 1 - Fluxo de Caixa Estimado para a Produção de mix 100\% Açúcar

\begin{tabular}{|c|c|c|c|c|c|c|c|c|c|c|c|}
\hline & 1 & 2 & 3 & 4 & 5 & 6 & 7 & 8 & 9 & 10 & 11 \\
\hline Receita Bruta & 321.901 & 413.519 & 448.037 & 491.062 & 515.107 & 533.225 & 561.078 & 590.386 & 621.225 & 653.675 & \\
\hline CPV & -227.333 & -237.427 & -253.964 & -276.839 & -290.808 & -303.942 & -319.818 & -336.524 & -354.102 & -372.599 & \\
\hline Despesas Administrativas & -24.263 & -25.743 & -27.025 & -28.335 & -29.667 & -31.062 & -32.521 & -34.050 & -35.650 & -37.326 & \\
\hline Despesas Com Vendas & -13.572 & -13.961 & -15.479 & -17.464 & -18.661 & -19.504 & -20.523 & -21.595 & -22.723 & -23.910 & \\
\hline (=) EBIT & 56.733 & 136.388 & 151.570 & 168.423 & 175.970 & 178.718 & 188.216 & 198.218 & 208.750 & 219.841 & \\
\hline Imposto de Renda e CSLL & -19.289 & -46.372 & -51.534 & -57.264 & -59.830 & -60.764 & -63.994 & -67.394 & -70.975 & -74.746 & \\
\hline Depreciação & 15.839 & 16.620 & 17.777 & 19.379 & 20.357 & 21.276 & 22.387 & 23.557 & 24.787 & 26.082 & \\
\hline Investimentos & -11.996 & -15.410 & -16.696 & -18.299 & -19.196 & -19.871 & -20.909 & -22.001 & -23.150 & -24.359 & \\
\hline Perpetuidade & & & & & & & & & & & 1.229 .373 \\
\hline (=) Fluxo de Caixa Empresa & 41.287 & 91.226 & 101.117 & 112.239 & 117.301 & 119.359 & 125.701 & 132.380 & 139.412 & 146.818 & 1.229 .373 \\
\hline
\end{tabular}

Fonte: Elaborado pelos autores

Tabela 2 - Fluxo de Caixa Estimado para a Produção de mix 60,68\% açúcar e 39,32\% etanol

\begin{tabular}{|c|c|c|c|c|c|c|c|c|c|c|c|c|}
\hline & $\mathbf{0}$ & 1 & 2 & 3 & 4 & 5 & 6 & 7 & 8 & 9 & 10 & 11 \\
\hline (-) Despesas Administrativas & & -39.984 & -42.423 & -44.536 & -46.696 & -48.891 & -51.189 & -53.595 & -56.114 & -58.751 & -61.512 & \\
\hline (=) EBIT & & 88.060 & 237.142 & 251.868 & 262.641 & 264.488 & 265.133 & 279.250 & 294.118 & 309.775 & 326.263 & \\
\hline (-) Imposto de Renda e CSLL & & -29.940 & -80.628 & -85.635 & -89.298 & -89.926 & -90.145 & -94.945 & -100.000 & -105.323 & -110.929 & \\
\hline (+) Depreciação & & 15.839 & 18.269 & 19.474 & 20.959 & 21.901 & 22.913 & 24.110 & 25.369 & 26.694 & 28.089 & \\
\hline
\end{tabular}

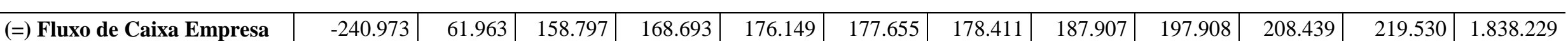
Fonte: elaborado pelos autores 
Pode-se estimar o valor da empresa, na hipótese de que sua operação fosse realizada apenas pelas duas unidades capazes de produzir açúcar e com o mix produtivo $100 \%$ açúcar, com base no exposto (DAMODARAN, 2002).

Valor da Empresa $=\sum_{t=1}^{t=n} \frac{F C \text { da Empresa }}{n} ;$ Valor da Empresa $=R \$ 944.822$

O próximo passo do estudo foi o levantamento dos valores dos ativos da unidade produtiva do grupo que possui apenas a capacidade de gerar etanol. Para tanto, foram analisados os balancetes do grupo para que fosse possível estimar o valor dos ativos produtivos da destilaria desta unidade e, com base nos dados consultados junto à contabilidade do grupo, o valor destes ativos é de R \$ 240,973 milhões.

Para a simulação do valor atual da organização, utilizando os investimentos da destilaria como prêmio pela opção do uso de mix produtivo entre açúcar e etanol, o primeiro passo foi estimar o mix produtivo que ofertaria o menor risco à empresa, com base no método de otimização de risco (DAMODARAN, 2002):

$W_{A}=\left[\sigma_{B}^{2}-\left(\rho_{A, B} \times \sigma_{A} \times \sigma_{B}\right)\right] /\left[\left(\sigma_{A}^{2}+\sigma_{B}^{2}\right)-\left(2 \times \rho_{A, B} \times \sigma_{A} \times \sigma_{B}\right)\right]$

Em que:

$W_{A}=$ Proporção otimizada ao risco para o produto $\mathrm{A}$;

$\rho_{A, B}=$ Correlação entre as variações dos produtos A e B;

$\sigma_{A}^{2}=$ Variância das variações de preço do produto A;

$\sigma_{B}^{2}=$ Variância das variações de preço do produto B.

Considerando como produto A o açúcar e produto B o etanol, a Tabela 3 traz a série histórica de preços da empresa cuja produção é vendida à Copersucar.

Tabela 3 - Preços Históricos dos produtos em Unicop (Unidade de conversão da cooperativa)

\begin{tabular}{c|c|c|c|c|c}
\hline \multirow{2}{*}{ Safra } & $\mathbf{B}$ & $\mathbf{A}$ & \multirow{2}{*}{ Safra } & B & A \\
\cline { 2 - 3 } \cline { 5 - 6 } & Etanol & Açúcar & & Etanol & Açúcar \\
\hline $\mathbf{2 0 0 8 / 1}$ & 27,88 & 27,24 & $\mathbf{2 0 1 2 / 1}$ & 39,83 & 47,30 \\
\hline $\mathbf{2 0 0 8 / 2}$ & 26,57 & 32,68 & $\mathbf{2 0 1 2 / 2}$ & 40,59 & 42,02 \\
\hline $\mathbf{2 0 0 9 / 1}$ & 23,68 & 29,65 & $\mathbf{2 0 1 3 / 1}$ & 41,01 & 39,72 \\
\hline
\end{tabular}


Tabela 3 - Preços Históricos dos produtos em Unicop (Unidade de conversão da cooperativa)

\begin{tabular}{l|l|l|l|l|l}
\hline $\mathbf{2 0 0 9 / 2}$ & 32,66 & 36,98 & $\mathbf{2 0 1 3 / 2}$ & 45,49 & 41,81 \\
\hline $\mathbf{2 0 1 0} / \mathbf{1}$ & 28,41 & 36,48 & $\mathbf{2 0 1 4 / 1}$ & 43,16 & 41,58 \\
\hline $\mathbf{2 0 1 0} / \mathbf{2}$ & 36,91 & 39,73 & $\mathbf{2 0 1 4 / 2}$ & 44,20 & 44,38 \\
\hline $\mathbf{2 0 1 1} / \mathbf{1}$ & 45,17 & 46,78 & $\mathbf{2 0 1 5 / 1}$ & 42,61 & 44,18 \\
\hline $\mathbf{2 0 1 1 / 2}$ & 50,07 & 42,20 & $\mathbf{2 0 1 5 / 2}$ & 52,55 & 56,00 \\
\hline
\end{tabular}

Fonte: Adaptado dos registros da empresa.

Desta forma, utilizando as premissas expostas com base nas proposições da carteira de mínima variância (DAMODARAN, 2002); estimou-se a proporção do total de processamento de cana para ser destinado a açúcar em 75,97\%, logo, 24,03\% deveriam ser destinados à produção de etanol.

Porém o gestor de produção do grupo informou em entrevista que a capacidade produtiva da unidade que possui apenas a destilaria é de 39,32\% da moagem e produção total do grupo; com efeito, o emprego do mix calculado levaria a unidade produtora de etanol a operar abaixo de sua capacidade, ocasionando em um custo fixo irrecuperável. Portanto, a sugestão é que seja utilizado um mix de 60,68\% de açúcar e 39,32\% de etanol, pois é o máximo suportado pela destilaria. O FC da unidade produtiva para açúcar e etanol foi demonstrado na Tabela 2.

Comparando o valor presente estimado da empresa contemplando as produções tanto de açúcar quanto etanol, tendo em vista o retorno esperado para cada um dos cenários propostos e seus respectivos investimentos observa-se:

$V P$ da Produção de Etanol $=R \$ 1.449 .810-R \$ 944.822=R \$ 504.987$

O VP da empresa com a produção de etanol não considerou o investimento de R\$ 240.973 no ano "0". Assim, descontando o prêmio (valor do investimento na construção da destilaria) encontra-se como Valor Presente Líquido da operação com o mix proposto $\mathrm{R} \$$ 264,014 milhões.

O terceiro cenário de análise visa estimar o valor presente da empresa considerando o acréscimo da cogeração de energia em sua operação e, para tanto, foram consultados os balanços para levantar o valor dos ativos produtivos das termoelétricas presentes no grupo. Segundo os dados presentes nos balanços, o valor total destes ativos totalizavam R 146,219 milhões e será considerado como investimento inicial para adição da energia ao portfólio do grupo. 
Quanto à operação produtiva de açúcar e etanol, o mix empregado é o mesmo proposto para o cenário anterior, pois a geração de energia elétrica por meio do bagaço de cana não concorre com a produção dos demais produtos. Isto posto, o acréscimo dos custos e receitas provenientes da cogeração de energia e o investimento para a instalação da capacidade de cogeração resultam no FC previsto na Tabela 4.

Partindo destas premissas, o cálculo do valor presente estimado da empresa (em milhares de reais) resulta em: Valor da Empresa $=R \$ 1.852 .821$

Desta maneira, analisando, comparativamente o escalonamento dos valores agregados pela diversificação produtiva entre açúcar e etanol e o incremento da cogeração de energia elétrica, o valuation da termoelétrica é:

$V P$ da Produção de Energia $=R \$ 1.852 .821-R \$ 1.449 .810=R \$ 403.011$ 
Tabela 4 - Fluxo de Caixa Estimado para a Produção de mix 60,68\% açúcar e 39,32\% etanol e cogeração de energia elétrica via queima de biomassas

\begin{tabular}{|c|c|c|c|c|c|c|c|c|c|c|c|c|}
\hline & $\mathbf{0}$ & 1 & 2 & 3 & 4 & 5 & 6 & 7 & 8 & 9 & 10 & 11 \\
\hline Receita Bruta & & 840.418 & 1.063 .008 & 1.127 .566 & 1.200 .022 & 1.240 .166 & 1.281 .880 & 1.344 .773 & 1.410 .930 & 1.480 .524 & 1.553 .731 & \\
\hline (-) CPV & & -583.274 & -672.295 & -716.653 & -771.350 & -806.046 & -843.277 & -887.325 & -933.675 & -982.445 & -1.033 .763 & \\
\hline (-) Despesas Administrativas & & -39.984 & -42.423 & -44.536 & -46.696 & -48.891 & -51.189 & -53.595 & -56.114 & -58.751 & -61.512 & \\
\hline (-) Despesas Com Vendas & & -34.894 & -40.248 & -42.902 & -46.174 & -48.250 & -50.478 & -53.115 & -55.889 & -58.809 & -61.881 & \\
\hline (=) EBIT & & 182.266 & 308.041 & 323.475 & 335.802 & 336.979 & 336.936 & 350.738 & 365.253 & 380.519 & 396.576 & \\
\hline $\begin{array}{l}\text { (-) Imposto de Renda e } \\
\text { CSLL }\end{array}$ & & -61.970 & -104.734 & -109.981 & -114.173 & -114.573 & -114.558 & -119.251 & -124.186 & -129.376 & -134.836 & \\
\hline (+) Depreciação & & 15.839 & 18.269 & 19.474 & 20.959 & 21.901 & 22.913 & 24.110 & 25.369 & 26.694 & 28.089 & \\
\hline (-) Investimentos & -146.219 & -11.996 & -15.173 & -16.094 & -17.128 & -17.701 & -18.297 & -19.195 & -20.139 & -21.132 & -22.177 & \\
\hline Perpetuidade & & & & & & & & & & & & 2.241 .171 \\
\hline
\end{tabular}

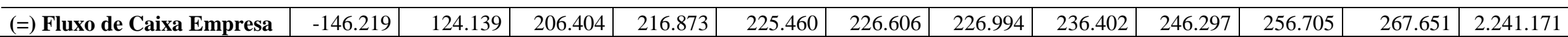

Fonte: elaborado pelos autores

Descontando da opção o valor bruto dos investimentos necessários para a implementação das unidades termoelétricas (R \$ 146.219), chegou-se a um resultado de Valor Presente Líquido de R\$256,792 milhões para o adendo da energia no portfólio.

Portanto, pode-se inferir que o Valor Presente Líquido final da empresa, adicionado dos valores agregados pelos investimentos em diversificação de seu portfólio será de:

$$
\begin{gathered}
V P L_{F}=V P L_{\text {Açúcar }}+V P L_{\text {Etanol }}+V P L_{\text {Energia }} \\
V P L_{F}=R \$ 944.822+R \$ 264.014+R \$ 256.792=R \$ 1.465 .629
\end{gathered}
$$


Nota-se, portanto, elevado incremento no valor da empresa proveniente dos possíveis investimentos em diversificação de seu portfólio, adicionando à produção de açúcar as opções de se diversificar os produtos finais básicos (ao se colocar a opção da produção de etanol) e ainda aproveitar o bagaço (que inicialmente seria apenas um descarte do processo industrial) para a cogeração de energia elétrica. Isso pode ser observado no estudo de (PANTOJA et al., 2016) que mostra que as empresas que optaram por uma produção flexível possuem um valor presente de fluxo de caixa maior em comparação com as usinas que optam por apenas por um dos dois produtos.

Segundo os gestores, todos os anos a decisão do mix produtivo a ser adotado cabe totalmente à gestão, sendo que, após esta decisão o valor escolhido é levado à cooperativa, que, por sua vez, analisa os cenários econômicos concomitantemente às intenções de produção de todas as Usinas cooperadas para que, só assim, sugira às usinas as cotas de cada tipo de produto que estão deverão produzir.

Isto posto, na quarta e última etapa deste estudo, foram projetadas as árvores de distribuição binomial para as possibilidades da variação dos preços tanto para o açúcar quanto para o etanol, visando estimar o resultado final do valor da empresa no momento em que os gestores optem pelo mix produtivo. Para padronizar e melhorar a assertividade dos cálculos foi calculada a correlação entre o risco e o retorno da produção de cada um dos itens, para que assim fosse simulada qual seria a melhor decisão a ser adotada. Modelo este muito semelhante ao adotado por (DIAS et al., 2011) que optou por modelar as incertezas do preço em relação ao mix de produção entre açúcar e etanol.

A margem de retorno estimada para o açúcar foi de $12,70 \%$, com um índice de coeficiente de variação entre risco e retorno de 0,86, enquanto, para o Etanol observa-se uma margem de retorno na casa de 36,98\% com coeficiente de variação em relação ao risco de 0,42. Ou seja, apesar de no caso do etanol a volatilidade dos preços apresentar-se maior do que para o Açúcar, quando comparada à margem de retorno, a operação pautada no etanol se apresenta mais vantajosa ao grupo. Isso corrobora o resultado estudado por Pantoja et al. (2016) que mostram que as usinas que optam pela opção de $100 \%$ açúcar no seu mix de produção possuem um valor presente menor do que aquelas que possuem um mix de $100 \%$ etanol.

Sendo assim, juntamente com as restrições produtivas observadas pelos dados básicos e entrevistas, temos que o único ponto limitante da operação do grupo seria a capacidade mínima da destilaria da unidade que é capaz apenas de produzir etanol, portanto, nesta fase do estudo, analisou-se como decisão gerencial a possibilidade de alterar o mix de produção, como forma de minimizar o impacto das variações dos preços no portfólio produtivo. O Quadro 3 apresenta as 4 combinações possíveis que geraram uma árvore polinomial. 
Quadro 3 - Mix optado de acordo com a Variação dos Preços

\begin{tabular}{|l|l|}
\hline $\begin{array}{l}\text { Aumento nos preços de açúcar e aumento nos } \\
\text { preços de etanol }\end{array}$ & $\begin{array}{l}\text { Nesta situação, respeitando a relação de risco e } \\
\text { retorno entre os preços dos produtos, a proposta é de } \\
\text { que o grupo opere em um mix 70\% etanol e 30\% } \\
\text { açúcar, cuja taxa de risco seria de 12,50\%; }\end{array}$ \\
\hline $\begin{array}{l}\text { Aumento nos preços do açúcar e queda nos preços } \\
\text { de etanol }\end{array}$ & $\begin{array}{l}\text { Para esta possibilidade, respeitou-se a limitação } \\
\text { produtiva do etanol exposta, resultando em um mix } \\
60,68 \% \text { açúcar e 39,32\% etanol, com o risco de } \\
10,60 \% ;\end{array}$ \\
\hline $\begin{array}{l}\text { Queda nos preços de açúcar e aumento nos preços } \\
\text { de etanol }\end{array}$ & $\begin{array}{l}\text { Neste cenário, o mix proposto foi de 100\% etanol, que } \\
\text { resulta em 15,53\% de risco; }\end{array}$ \\
\hline $\begin{array}{l}\text { Queda nos preços de açúcar e queda nos preços de de } \\
\text { etanol }\end{array}$ & $\begin{array}{l}\text { Para minimizar as perdas decorrentes da baixa de } \\
\text { preços a sugestão é de um mix com 90\% de etanol e } \\
\text { apenas 10\% de açúcar, com um risco de 14,43\%. }\end{array}$ \\
\hline
\end{tabular}

Fonte: elaborado pelos autores

Para a estimativa das árvores binomiais de comportamento dos preços e suas respectivas probabilidades neutras ao risco e de movimentações temos, para o açúcar, conforme Equações 8 e 9 (BRANDÃO; DYER; HAHN, 2005): $u=1,12 ; d=0,90$;

Isto posto, a árvore de movimentação projetada para os preços do açúcar é dada conforme a Figura 1. Para os preços de etanol, a distribuição projetada, com base nos mesmos conceitos, conforme demonstrado pela Figura 1, é dada por: $u=1,17 ; d=0,86$;

Assim, a simulação dos fluxos de caixa da organização foi feita pautada sempre em quatro possibilidades considerando os valores de mix propostos. Diante das incertezas relacionadas às variações de preços em cada ano e cada um dos cenários, estimou-se que a probabilidade de ocorrência de cada um destes seria igual, sendo assim, em cada ano há $25 \%$ de probabilidade para cada uma das combinações possíveis entre os comportamentos dos preços.

O cenário base para as projeções foi o de investimento em produção de energia, contemplando como investimento o valor estimado dos ativos produtivos da destilaria e das terrmoelétricas e considerando também as receitas provenientes da cogeração de energia elétrica. Cenário esse que foi estudado de maneira semelhante por (DIAS et al., 2011) onde o cenário base era a cogeração, mas que passava depois por uma expansão. Sendo assim, com estes cenários temos como possibilidades os seguintes fluxos de caixa a valor presente:

Os valores no interior da Figura 1 são recombinantes e, por isso, não foram apresentados para permitir uma melhor visualização dos resultados.

Atentar que em três nós inferiores os valores estão zerados, pois os menores valores do açúcar e etanol projetados não seriam suficientes para suportar a operação do grupo e, então, a sugestão seria a parada da produção de açúcar e etanol, por isso, os valores zerados. 
Figura 1 - Comportamento dos preços de Açúcar e Etanol com Base no TOR

\begin{tabular}{|c|c|c|c|c|c|}
\hline & & & car & & \\
\hline & & & & & 81,36 \\
\hline & & & & 72,90 & \\
\hline & & & 65,32 & & 65,32 \\
\hline & & 58,53 & & 58,53 & \\
\hline & 52,45 & & 52,45 & & 52,45 \\
\hline 47,00 & & 47,00 & & 47,00 & \\
\hline & 42,11 & & 42,11 & & 42,11 \\
\hline & & 37,74 & & 37,74 & \\
\hline & & & 33,81 & & 33,81 \\
\hline & & & & 30,30 & \\
\hline & & & & & 27,15 \\
\hline
\end{tabular}

\begin{tabular}{|c|c|c|c|c|c|}
\hline \multicolumn{6}{|c|}{ Etanol } \\
\hline & & & \multirow[b]{3}{*}{73,46} & \multirow[b]{2}{*}{85,80} & \multirow{2}{*}{100,22} \\
\hline & & & & & \\
\hline & & & & & 73,46 \\
\hline & & 62,89 & & 62,89 & \\
\hline & 53,84 & & 53,84 & & 53,84 \\
\hline 46,10 & & 46,10 & & 46,10 & \\
\hline & 39,46 & & 39,46 & & 39,46 \\
\hline & & 33,79 & & 33,79 & \\
\hline & & & 28,93 & & 28,93 \\
\hline & & & & 24,76 & \\
\hline & & & & & 21,20 \\
\hline
\end{tabular}

Fonte: Elaborado pelos Autores

Figura 2 - Valor da empresa Projetado para as variações de preços

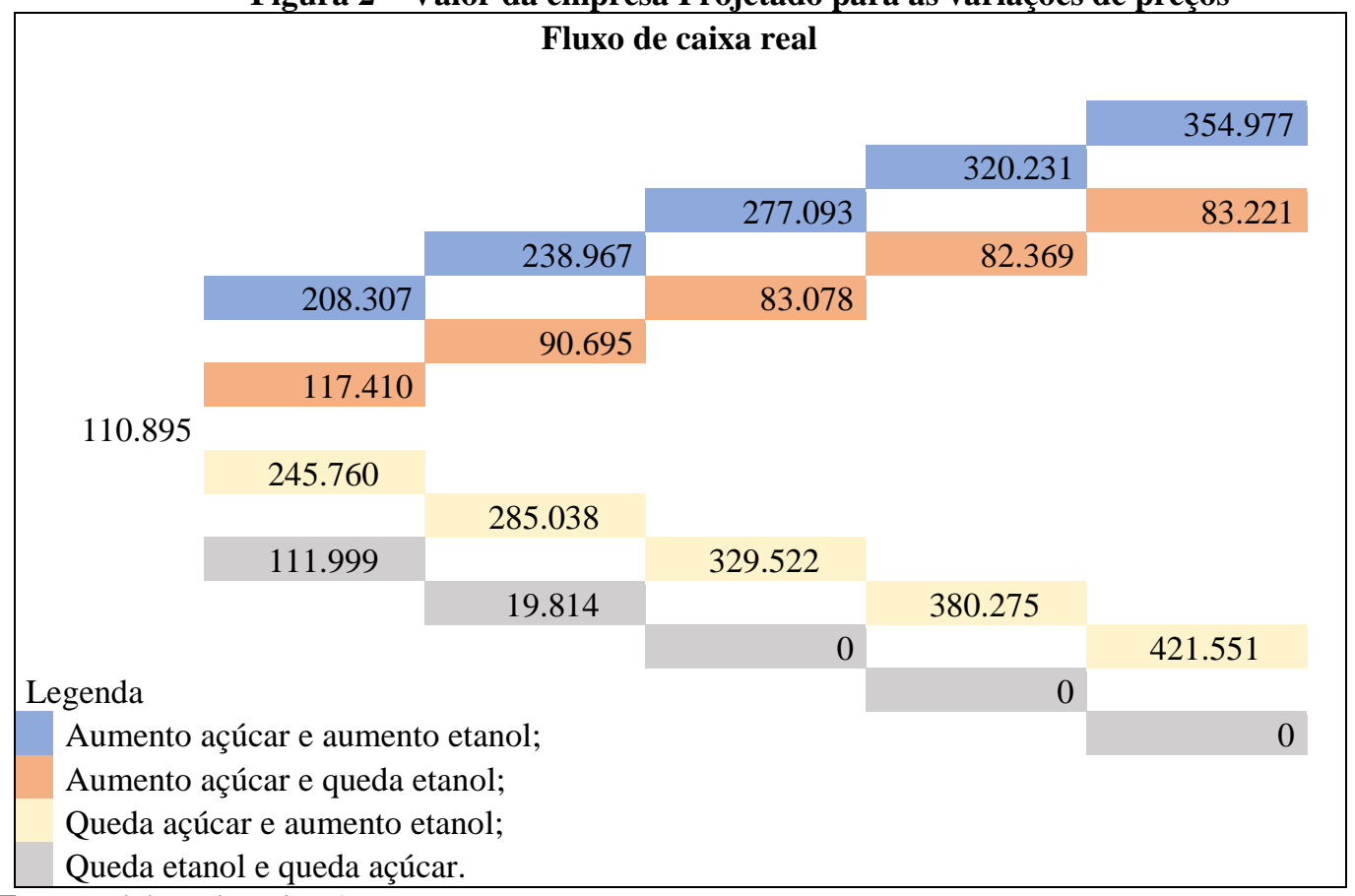

Fonte: Elaborado pelos Autores.

Diante disso, ponderando os valores obtidos com as projeções dos fluxos de caixa pela probabilidade de ocorrência de cada um dos cenários (25\%) tem-se:

Tabela 7 - Valor Estimado da Empresa ponderado pela probabilidade

\begin{tabular}{c|c|c|c|c|c|c|c}
\hline Ano & 0 & 1 & 2 & 3 & 4 & 5 & (perpetuidade) \\
\hline FCL & 110.895 & 170.869 & 158.629 & 172.423 & 195.719 & 214.937 & 1.674 .940 \\
\hline \multicolumn{7}{c}{ Fonte: Elaborado pelos Autores. }
\end{tabular}

$$
\text { Valor da } O p \text { ção }=R \$ 1.641 .093-R \$ 1.465 .630=R \$ 175.463
$$

Percebe-se, portanto, que incorporando ao método FCD as projeções das variações dos preços dos produtos com base no modelo das árvores binominais proposto, o resultado que leva 
em conta a flexibilidade gerencial do grupo em optar pela produção de um mix otimizado ou a produção somente de etanol traz um incremento substancial ao valor estimado da empresa em um horizonte de uma década. Tal resultado corrobora de outra forma os resultados encontrados por Pantoja et al. (2016) pois, identificaram que as empresas que optaram pelo método de flexibilizar a produção conseguem agregar mais valor.

\section{CONCLUSÃO}

O estudo buscou analisar por meio das opções reais o acréscimo de valor que poderia resultar a flexibilidade gerencial em alterar as opções do mix de produtivo em uma planta sucroenergética complexa para os três principais produtos do setor: açúcar, etanol e energia. Observou-se que esses investimentos, quando tratados isoladamente, criam valor e corroboram as evidências de mercado quanto aos investimentos realizados na ampliação da capacidade produtiva e diversificação dos setores.

No entanto, de forma original, esse estudo demonstrou a possibilidade de utilizar o conceito da teoria de portfólio para determinar o mix adequado de produção e condicioná-lo as condições produtivas, não obstante, foi possível modelar no curso do tempo estratégias distintas de adequação do portfólio em função da volatilidade do preço do etanol e do açúcar. A flexibilidade em alterar o mix resultou em um incremento de R 175 milhões que é maior que o investimento realizado na termelétrica e demonstra a importância desta gestão.

Assim, os resultados deste estudo demonstram as possibilidades e limitações para a extensão das técnicas de portfólio e opções reais às operações sucroenergticas, bem como pode proporcionar insights para o processo decisório de outras centenas de usinas do setor no país e de outros produtores quanto a importância econômica da flexibilidade em ajustar o mix de produção, assim como, gerar flexibilidade operacional para tanto.

Como limitações do estudo, pode-se levantar a grande dificuldade da empresa quanto a confiabilidade e assertividade de seus dados. Essa situação decorre de uma característica tradicional deste setor quanto a elevada eficiência operacional, porém ressentido de aplicações dos métodos de gestão equivalentes a sua importância econômica e complexidade organizacional.

Para estudos futuros são indicados: i) incluir a volatilidade da produção agrícola para definição do mix; ii) inclusão do potencial de criação de valor com investimentos em biorrefinarias; iii) criação de valor na adaptação das unidades produtivas para produção etanol a partir do milho em período de entressafra; iv) avaliação comparativa com outras empresas, com vistas a aumentar o nível de informação para fins de benchmark. 


\section{REFERÊNCIAS}

BASTIAN-PINTO, C. L.; BRANDÃO, L. E. T. Modelando Opções de Conversão com Movimento de Reversão à Média. Revista Brasileira de Finanças, São Paulo, v. 5, n. 2, p. 97 124, 2007.

BOOMSMA, T. K.; LINNERUD, K. Renewable energy investment under the risk of change in support schemes. Real Options Annual Conference. Oslo: Real Option Group. 2016. p. 1-6.

BOOMSMA, T. K.; MEADE, N.; FLETEN, S.-E. Renewable energy investments under different support schemes: A real options approach. European Journal of Operational Research, v. 220, n. 1, p. 225-237, 2012.

BRANDÃO, L. E.; DYER, J. S. Decision Analysis and Real Options: A Discrete Time Approach to Real Option Valuation. Annals of Operations Research, v. 135, n. 1, p. 21-39, 2005.

BRANDÃO, L. E.; DYER, J. S.; HAHN, W. J. Using Binomial Decision Trees to Solve RealOption Valuation Problems. Decision Analysis, v. 2, n. 2, p. 69-88, 2005.

BRANDÃO, L. E.; DYER, J. S.; HAHN, W. J. Volatility estimation for stochastic project value models. European Journal of Operational Research, v. 220, n. 3, p. 642-648, 2012.

CAMARGO, A. S. J.; OLIVEIRA, M. M. B. Eficiência Econômica no Setor Sucroalcooleiro: Uma Análise de Algumas Usinas do Estado de São Paulo. Organizações Rurais \& Agroindustriais, v. 13, n. 3, p. 330-343, 2011.

CASAGRANDE, E. E.; CEREZETTI, F. V. Investment theory and empirical approach: a discussion on difficulties. Latin American Journal Management for Sustainable

Development, v. 1, n. 1, p. 96-108, 2014.

CONAB. Perfil do Setor do Açúcar e do Álcool no Brasil. CONAB. Brasília, p. 81. 2013. (2318-3772).

COPELAND, T. E.; KOLLER, T.; MURRIN, J. Avaliação de Empresas: Valuation. 3a. ed. São Paulo: Makron Books, 2002.

COPELAND, T.; ANTIKAROV, V. Opções Reais: Um novo paradigma para reiventar a avaliação de investimentos. Rio de Janeiro: Campus, 2001.

COSTA, L. D. A.; SAMANEZ, C. P. Análise de Projetos de Investimento no Setor Petroquímico através da Teoria de Opções Reais. Interciência, v. 39, n. 2, p. 85-90, 2014.

COX, J. C.; ROSS, S. A.; RUBINSTEIN, M. Option Pricing: A Simplified Approach. Journal of Financial Economics, v. 7, n. 3, p. 229-263, 1979.

CUERVO, F. I.; BOTERO, S. B. Aplicación de las opciones reales en la toma de decisiones en los mercados de electricidad. Estudios Gerenciales, v. 30, n. 133, p. 397-407, 2014.

CUNHA, C. A.; MEDEIROS, J. A. V.; WANDER, A. E. Use of real options to evaluate a beef cattle feedlot. Custos e @gronegócio online, v. 10, n. 1, p. 212-227, 2014.

CUNHA, M. F.; MARTINS, E.; ASSAF NETO, A. Avaliação de empresas no Brasil pelo fluxo de caixa descontado: evidências empíricas sob o ponto de vista dos direcionadores de valor nas ofertas públicas de aquisição de ações. Revista de Administração, v. 49, n. 2, p. 251-266, 2014.

DAMODARAN, A. Avaliação de investimentos: ferramentas e técnicas para a determinação do valor de qualquer ativo. $2^{\text {a }}$ Edição. ed. Rio de Janeiro: Qualtymark, 2002.

DIAS, A. C. A. E. M. et al. Flexibilidade e incerteza em projetos de agronegócios: investindo numa planta de cogeração. Revista de Administração Mackenzie, v. 12, n. 4, p. 105-126, 2011.

FAO. Food and Agricultural commodities production / Countries by commodity. FAO. [S.1.]. 2013. 
FREZATTI, F. et al. Decisões de Investimento em Ativos de Longo Prazo nas Empresas Brasileiras: Qual a Aderência ao Modelo Teórico? Revista de Administração Contemporânea, Rio de Janeiro, v. 16, n. 1, p. 1-22, 2012.

GARCIA, J. R.; LIMA, D. A. L. L.; VIEIRA, A. C. P. A nova configuração da estrutura produtiva do setor sucroenergético brasileiro: panorama e perspectivas. Revista de Economia Contemporânea, v. 19, n. 1, p. 162-184, 2015.

GODOY, A. S. Pesquisa qualitativa em estudos organizacionais: paradigmas, estratégias e métodos. In: GODOI, C. K.; BANDEIRA-DE-MELO, R. B.; SILVA, A. B. Estudo de caso qualitativo. São Paulo: Saraiva, 2006. p. 115-146.

GRAHAM, J. R.; HARVEY, C. R. The theory and practice of corporate finance: evidence from the field. Journal of Financial Economics, v. 60, n. 2-3, p. 187-243, 2001.

HETTINGA, W. G. et al. Understanding the reductions in US corn ethano lproduction costs: An experience curve approach. Energy Policy, v. 37, n. 1, p. 190-203, 2009.

INIESTA, J. B.; SOLIÑO, A. S.; GALERA, A. L. Application of Real Options Theory to the Assessment of Public Incentives for Onshore Wind Energy Development in Spain. International Journal of Energy Economics and Policy, v. 5, n. 3, p. 791-800, 2015.

JOAQUIM, M. S. et al. Aplicação da Teoria das Opções Reais na Análise de Investimentos em Sistemas Agroflorestais. Cerne, v. 21, n. 3, p. 439-447, 2015.

JOHANN, E. R. et al. Metodologia Clássica e Método Multi-Índice na Avaliação Financeira de Projetos de Investimento: Um Estudo de Caso na Empresa Alfa. Gestão e Desenvolvimento, v. 11, n. 1, p. 91-112, 2014.

JORNALCANA. Anuário da cana 2015: safra 2014/2015. Procana. Ribeirão Preto. 2015.

KEYNES, J. M. A Teoria Geral do Emprego, do Juro e da Moeda. São Paulo: Nova Cultural Ltda, 1996.

KIENZLE, F.; ANDERSSON, G. Valuing Investments in Multi-Energy Generation Plants under Uncertainty: A Real Options Analysis. IAEE European conference. Viena: Swiss Federal Institute of Technology Zurich. 2009. p. 141-156.

MACEDO, M. A. D. S.; NARDELLI, P. M. Teoria de Opções Reais e viabilidade econômicofinanceira de projetos agroindustriais: o caso da opção de abandono. Organizações Rurais \& Agroindustriais, v. 13, n. 1, p. 109-123, 2011.

MANDEGARI, M. A.; FARZAD, S.; GÖRGENS, J. F. Economic and environmental assessment of cellulosic ethanol production scenarios annexed to a typical sugar mill. Bioresource Technology, v. 224, p. 314-326, 2017.

MANOEL, A. A. S.; SANTOS, D. F. L.; MORAES, M. B. C. Determinantes do Endividamento na Indústria Sucroenegética Brasileira: Análise a partir das Teorias de Estrutura de Capital.

Organizações Rurais \& Agroindustriais, v. 18, n. 2, p. 140-153, 2016.

MILLER, L. T.; PARK, C. S. Decision Making under uncertainty - Real Options to the Rescue? The Engineering Economist, v. 47, n. 2, p. 105-150, 2002.

MINISTÉRIO DE MINAS E ENERGIA DO BRASIL. Resenha Energética. MINISTÉRIO DE MINAS E ENERGIA DO BRASIL. Brasília, p. 31. 2016.

MOTA, J. C. V. D.; MACHADO, A. G. C.; MORAES, W. F. A. D. Condicionantes para Exportação no Setor Sucroenergético Brasileiro. Revista de Economia e Sociologia Rural, v. 22, n. 4, p. 705-724, 2015.

PAMPLONA, E. D. O. et al. Evaluating Energy Sector Investments: Calculating Volatility. Mathematical Problems in Engineering, v. ID 128309, p. 1-9, 2013.

PANTOJA, C. D. S. Teoria das Opções Reais: Uma Abordagem em Energia Eólica.

Pontifícia Universidade Católica do Rio de Janeiro. Rio de Janeiro, p. 139. 2013. 
PANTOJA, D. E. L. et al. Valoração econômica da flexibilidade de produção em diferentes regiões do setor sucroalcooleiro brasileiro. Revista Brasileira de Gestão de Negócios, v. 18, n. 60, p. 226-244, 2016.

PINDYCK, R. S. Investments of uncertain cost. Journal of Financial Economics, v. 34, n. 1, p. 53-76, 1993.

REZENDE, M. L.; RICHARDSON, J. W. Economic feasibility of sugar and ethanol production in Brazil under alternative future prices outlook. Agricultural Systems, v. 138, p. 77-87, 2015.

RODRIGUES, P. H. D. F. et al. Avaliação de empresas start-up por Opções Reais: o caso do setor de biotecnologia. Gestão \& Produção, v. 20, n. 3, p. 511-523, 2013.

SAMANEZ, C. P.; COSTA, L. D. A. Avaliação de opções de swing em contratos de gás natural usando um modelo de dois fatores. Produção, v. 24, n. 4, p. 760-775, 2014.

SANTOS, D. F. L.; ZOTES, L. P. Metodologias para valoração de pequenas e médias empresas. Revista Eletrônica do Mestrado Profissional em Administração, v. 3, n. 1, p. 17-26, 2010.

SIMÕES, M. D. D. P. et al. Opções de swing no mercado brasileiro de energia elétrica. Revista de Economia e Administração, v. 10, n. 4, p. 591-610, 2011.

SPETIC, W.; MARQUEZ, P.; KOZAK, R. Critical Areas and Entry Points for SustainabilityRelated Strategies in the Sugarcane-Based Ethanol Industry of Brazil. Business Strategy and the Environment, v. 21, n. 6, p. 370-386, 2012.

STEINER, A. O uso de estudos de caso em pesquisas sobre política ambiental: vantagens e limitações. Revista de Sociologia e Política, v. 19, n. 38, p. 141-158, 2011.

TOURINHO, O. A. F. The Valuation of Reserves of Natural: An Option Pricing Approach. University of California. Berkeley, p. 103. 1979.

TRIGEORGIS, L. Real options: Managerial flexibility and strategy in resource allocation. Cambridge: MIT Press, 1996. 427 p.

TVERSKY, A.; KAHNEMAN, D. Rational choice and the framing of decisions. Journal of Business, v. 59, n. 4, p. 251-278, 1986.

YIN, R. K. Estudo de Caso: Planejamento e Métodos. 5a. ed. Porto Alegre: Bookman, 2015. 